\title{
A GREAT LEPROSY WORKER
}

The news of the death of Dr. F. G. Rose, Medical Superintendent of the Leper Hospital, Mahaica, British Guiana, will bring deep regret to a wide circle of friends not only in the Caribbean but throughout the world.

Dr. Rose might have held a high position in other lines of medicine, but some seventeen years ago he felt a call to a kind of work which few were willing to undertake. At that time the Mahaica leper Hospital was in a pitiable condition, little was done to treat the patients or alleviate their miserable condition, the site was swampy and malarious. For the rest of his life ID. Rose gave himself up wholeheartedly to the service of these unfortunate people.

Dr. Rose was a good physician but he was more than that. He was a Christian gentleman with high ideals and broad culture. Among his hobbies were music and drama and he gave the patients the full benefit of his talents. He trained an excellent band and organised entertainments. He introduced various industries and constructed the second best cricket ground in the Colony, encouraging the patients in all forms of sport and healthy recreation. 
A few months ago the writer had the privilege of spending two weeks with Dr. Rose and studying his methods and noticed how he treated the patients as his children and they addressed him affectionately as "Daddy." Day and night he was at their call and he was never too tired or pre-occupied to give them the utmost of his skill and service. He took particular interest in the young and founded a home for leprous children and another for the children of leprous parents.

But Dr. Rose was not content with the alleviation of the sufferings of his patients. He took a wider view and aimed at the control and ultimate eradication of leprosy. In spite of considerable opposition and indifference on the part of the public and the authorities he succeeded in establishing a number of leprosy clinics all over the colony, so that carly non-infectious cases might be treated and discharged cases kept under supervision. Although he had no medical assistant he so organised his work in the Leper Hospital that he could be absent and attend these clinics. This entailed travelling long distances on rough roads, and it is not unlikely that the great strain of his double duties undermined his health and shortened his life.

In British Guiana segregation for leprosy is compulsory, but the law had seldom to be put into force as patients entered the Leper Hospital voluntarily, attracted by the news of Dr. Rose's skill and sympathy.

Dr. Rose calculated that there are still in British Guiana about one thousand people suffering from leprosy, but there are lew infectious cases that are not segregated and almost all were known to him and under his supervision and treatment. It may be said that leprosy in the Colony is today almost, if not entirely, under control. It will not be easy to fill Dr. Rose's place, but it is to be hoped that adequate provision will be made for continuing his many activities and carrying on his great work, for it is only by continuous care and supervision that control can be maintained till leprosy is entirely eradicated from the Colony.

(From an article by Dr. E. Muir in the Caribbean Medical Journal.) 